\title{
ASPAYM Córdoba a fondo
}

\section{ASPAYM Cordoba in detail}

\section{Palabras clave}

Lesión medular, discapacidad, discapacidad física, diversidad funcional, integración social, Córdoba, ASPAYM Córdoba.

\section{Keywords}

Spinal cord, disability, physical disability, functional diversity, social integration, Córdoba, ASPAYM Córdoba.
La Asociación de Personas con Lesión Medular y Gran Discapacidad Física de Córdoba - ASPAYM (en adelante ASPAYM Córdoba) es una asociación de personas con lesión medular y gran discapacidad física que nace en 2008 como ALMA y cambia su nombre en 2012 para unirse a la Federación Nacional ASPAYM.

La lesión medular es la pérdida o alteración de la movilidad, de la sensibilidad o del sistema nervioso autónomo, ocasionada por un trastorno de las estructuras nerviosas alojadas en el canal medular. Dependiendo de la localización del daño, podrá afectar a órganos pélvicos, extremidades inferiores, tronco y abdomen y extremidades superiores, provocando desde dificultades leves en la movilidad, hasta paraplejia o tetraplejia.

El objetivo de la asociación es mejorar la calidad de vida de todas las personas con movilidad reducida, promoviendo su desarrollo integral y trabajando por la integración social y laboral.

Durante el año 20 I 5 se ha llevado a cabo el Proyecto "ASPAYM Córdoba a fondo", realizando entrevistas a varios de los socios de ASPAYM Córdoba para conocer la realidad de estas personas que han sufrido situaciones difíciles y dolorosas,

\section{Esther Carrasco Rivero}

<aspaymcordoba.ts@gmail.com>

Asociación ASPAYM Córdoba. Psicóloga en Asociación ASPAYM Córdoba (España)
Para citar:

Carrasco, E. (20I 5): “ASPAYM Córdoba a fondo", Revista Española de Discapacidad, 3 (2): I39-I43.

Doi: <http://dx.doi.org/IO.5569/23405IO4.03.02.IO> 
tanto que han hecho cambiar su forma de ver y afrontar la vida. La finalidad es ofrecer sus historias a la población general para aumentar la conciencia social sobre estas lesiones y facilitar la inclusión social, psicológica y laboral de los afectados. Éste es el resultado:

Hace 44 años sufre un accidente de tráfico, recuerda el día perfectamente, tenía 20 años recién cumplidos:

"El I9 de octubre de I970, estaba trabajando canalizando un arroyo en Marchena, aún no había amanecido, iba en mi moto por la carretera de Palma del Río a Écija. Venían tres camiones de frente con las luces encendidas y no vi el carro tumbado en mi carril".

Se rompió las vértebras cervicales, y durante el traslado hasta Sevilla, improvisado por personas de a pie, sufrió más daños y fue muy doloroso. Tuvo momentos de pérdida de consciencia pero lo recuerda casi todo. Los daños que sufre le dejan con tetraplejia.

"Cuando volví a casa ponía buena cara a los demás, pero quería morirme, no veía salida. ¿Qué voy a hacer en esta vida si no sirvo para nada?, ¿quién me va a querer? Nadie creía que yo sirviera para algo, antes tenía éxito con las mujeres y ahora no quería arriesgarme a que me rechazaran, así que no intentaba nada, ni siquiera hablaba con ninguna".

Este es Salvador, uno de nuestros socios. Nos cuenta su historia con tanto realismo que parece que podemos ver su vida pasar. Hechos innegables, ilusiones perdidas, momentos duros, y luego... la luz de nuevo.

"El psiquiatra insistía en que 'todos servimos para algo', y que 'hay personas en silla de ruedas que valen más que muchos de los que andan'. A partir de ahí comencé a estudiar y eso me animó. Luego me ocupé de las tierras de mi padre y junto a mis hermanos, compramos más tierras y vivimos de ello".

También se atrevió con el amor, su asignatura pendiente:
"Hasta que no vi en un viaje gente como yo que había conseguido tener pareja, no me atreví a intentarlo". Años después se casó y se encuentra feliz y realizado. "Mantengo una lucha permanente, en cuanto pasa el invierno no paro en casa, quiero viajar en verano todo el tiempo que se pueda. Salgo mucho, hablo con la gente, me informo sobre el campo y voy cambiando los cultivos".

Escribió un libro y tiene otro en mente.

Rafa sufre un accidente cuando realiza una zambullida en San Sebastián, donde se encuentra trabajando como policía nacional. Reconoce que estaba en su mejor momento. "Lo tenía todo, era joven, tenía coche, moto", y allí era donde quería quedarse a vivir y trabajar, "me gusta mucho la montaña, el norte de España y mi trabajo lo hacía por vocación”.

Despierta en el hospital desorientado, con un arco en la cabeza y el cuerpo lleno de tubos. "La situación me resultaba absurda”. Se produjo una lesión medular en $\mathrm{C}_{6}-\mathrm{C}_{7}$, no tiene sensibilidad ni musculatura ninguna desde el pecho hacia abajo. Tampoco en antebrazos y manos. Le practicaron una operación para tensar el tendón en la mano derecha y poder usarla como pinza para coger cosas.

Tras 20 días en la UCI, y casi nueve meses en planta, se replantea su vida:

"Fueron momentos duros pero pensé que es una nueva vida, un nuevo reto, que tenía que partir de cero".

Pasó momentos muy duros, lo considera "una oportunidad obligada para ver, sentir y vivir otro tipo de vida". "Encuentras gente muy especial, vives cosas que te enriquecen como persona, sientes que las cosas no podían ser de otra forma".

“Todos los días vas aprendiendo, más de errores que otra cosa". Aprende cada día cosas que no le pueden enseñar en ningún sitio. "Los amigos no sabían que hacer conmigo al principio, yo era 


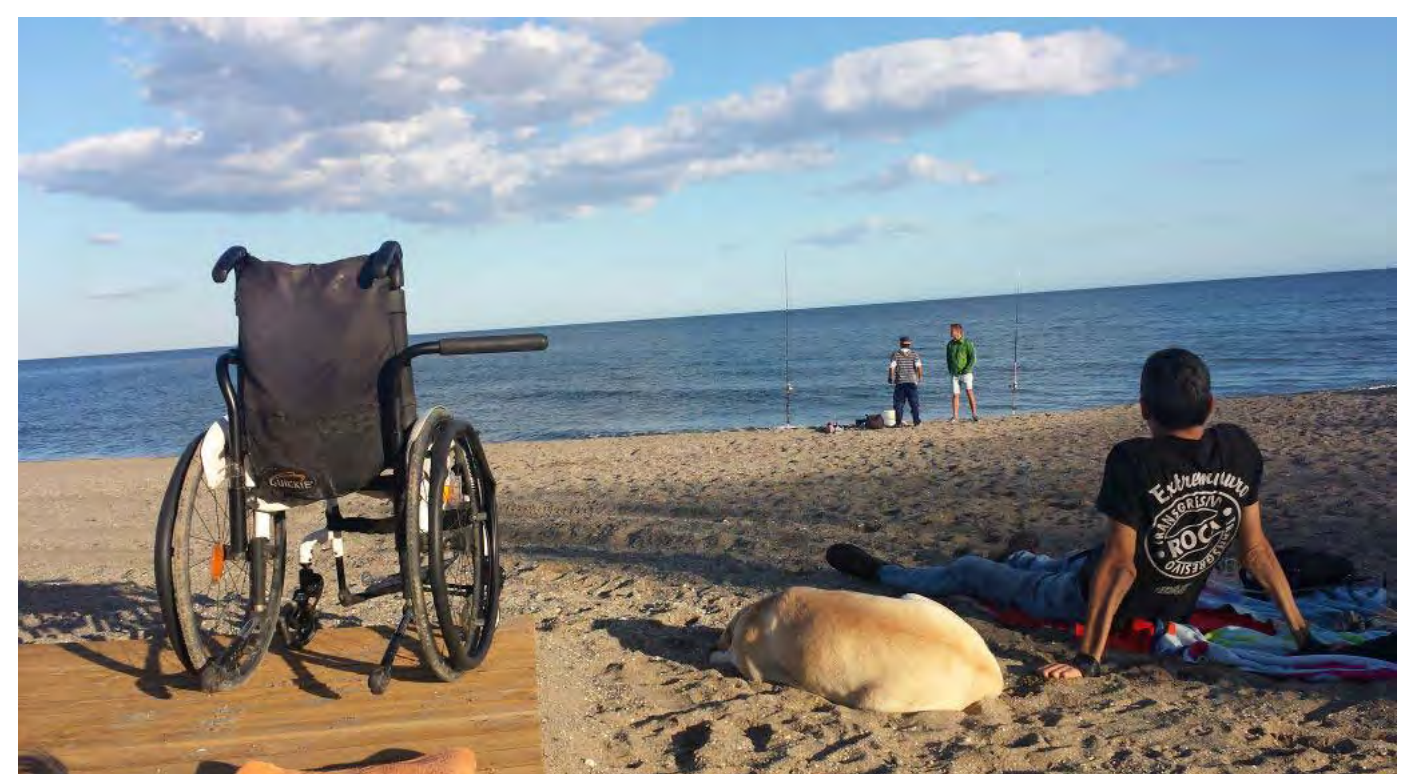

Nuestro compañero Rafael disfrutando de un día de playa.

el que los movía a todos y montaba los peroles cuando venía a Córdoba”.

"Yo antes vivía al límite: montaña, deportes, motos... ahora considero que vivo más al límite".

Y se refiere a vivir desde su silla de ruedas, en la que tiene muy poca movilidad y estabilidad, y puede caerse en cualquier momento. Y vive solo.

Lola sufrió un accidente de tráfico cuando derrapó la furgoneta de trabajo en el puerto de montaña de Despeñaperros: "noté un crack y no podía levantarme; pedía a Dios que no me muriera en aquella carretera tan fría”.

Conducía su novio, quien más tarde sería su marido: "se sentía culpable al principio, yo le dije que esto iba a ser muy duro y si quería podía dejar la relación; él me dijo que no se iba a ir de mi lado".

"Me di cuenta inmediatamente que eso era lo que tocaba y tenía que afrontarlo. Los dos primeros meses estuve aguantando con actitud positiva, queriendo mejorar pronto para hacer cosas. Luego reventé y me arroparon muy bien. Soy muy positiva, creo que es mejor así, la negatividad no te deja avanzar".

Recuerda que su estancia en el Hospital Nacional de Parapléjicos de Toledo fue muy buena, aprendió a manejar la silla y a valerse por sí misma. "Siempre he sido muy autónoma. Había mucho compañerismo y lo llevas bien, todos van en silla de ruedas”. Allí se sacó el carnet de conducir y se decidió a alquilar un piso junto a su novio al volver a Córdoba.

Se casó y tuvo dos hijos. Hace todo en su casa: compra, cocina, limpia... "hasta donde me llega el brazo". Y en la calle: traslada a los niños en su coche al colegio, a las actividades, a las citas con los amigos. Hace todo lo que quiere, y se considera feliz. También realiza charlas de prevención de accidentes de tráfico junto a ASPAYM Córdoba.

"Todavía me sorprendo de las cosas que puedo hacer, me supero cada día. Soy feliz. Esto es muy duro y te cuesta cada día, pero me quedo con el SÍ”. 


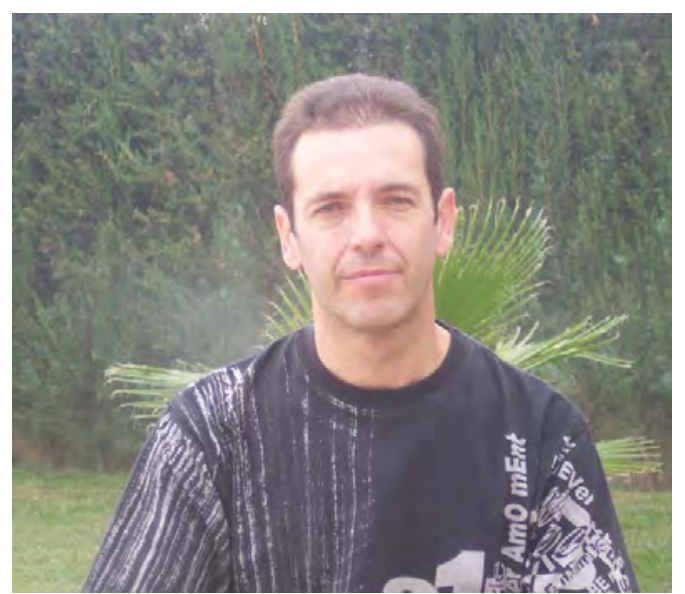

Manuel en uno de sus paseos.

En r996, Manuel llevaba una vida normalizada, con mujer y dos hijos de 2 y 4 años. Un día, mientras trabajaba como vigilante de seguridad, recibió tres disparos en un atraco a un banco. Sufrió una lesión medular, además de perforación en algunos órganos internos. "Supe que algo pasaba porque no me sentía las piernas".

Tras tres meses en la UCI, en los que surgieron muchas complicaciones, le trasladan al Hospital Nacional de Parapléjicos de Toledo, donde permanece un año.

"Allí es donde me encuentro con mi discapacidad cara a cara", la mayoría de los pacientes son parapléjicos y van en silla de ruedas, como él. Acompañado de su mujer, que pasa todo el día con él en el hospital, aprende a usar la silla y a realizar tareas básicas de la vida diaria; sin embargo refiere: "no lo aceptaba, no quería quedarme en una silla de ruedas para siempre, y aún no lo acepto”.

Acude a rehabilitación al Hospital Reina Sofía y posteriormente al Hospital San Juan de Dios. Sin embargo, su ánimo no mejora, continúa sintiéndose "triste, sin ganas de nada", afectándole a su día a día y a la relación con su familia: "no quería salir ni saber de los niños".

Su mujer ha estado siempre tratando de empujarle a hacer cosas y Manuel ha ido mejorando muy lentamente: "iba arrancándolo a la fuerza poco a poco".

Los hijos han jugado un papel fundamental, lo que les ha mantenido en un camino estable. Su hija, al contar con sólo dos años cuando ocurrió el accidente, siempre le ha conocido así y no ha tenido que aceptar el cambio, incluso quería realizar todas las tareas de cuidado, hasta llevar la silla. Sin embargo, su hijo, que tenía cuatro años, sí lo vivió con más complejidad y tardó en normalizar la situación. Hasta que no pasó la adolescencia no lo aceptó del todo.

Disfrutan de salidas de ocio frecuentes con familia y amigos, gustan de dar paseos, tomar una cerveza en una terraza, hacer peroles camperos y, sobre todo, pasar el verano en la playa.

Alfonso, socio y deportista, también tiene una gran historia:

“A los I 8 años sufrí un accidente de moto provocado por un coche que giró a la izquierda mientras yo adelantaba”. Estuve r 6 meses en hospitales: dos y medio en el Virgen del Rocío y el resto en San Juan de Dios, unidad de lesión medular. Muy buenos profesionales, sobre todo el monitor de silla de ruedas, me hacía caerme para que aprendiera a levantarme, no tenía piedad, y eso me ayudó mucho”.

El primer recuerdo tras el accidente fue muy duro:

"No se lo deseo ni a mi peor enemigo: darte cuenta de que no mueves las piernas, que no puedes hacer las cosas por ti mismo, que dependes de los sanitarios, de tu madre. Pero si te vienes abajo, ¿qué clase de vida vas a tener?”.

"No he echado muchas cuentas a mis limitaciones, he mirado hacia adelante; no me sirve mirar atrás y ver personas peor que yo, no puede ser una satisfacción, es una estupidez. Si miras atrás y ves que estás mejor que hace años, sí te sientes satisfecho de verdad". 


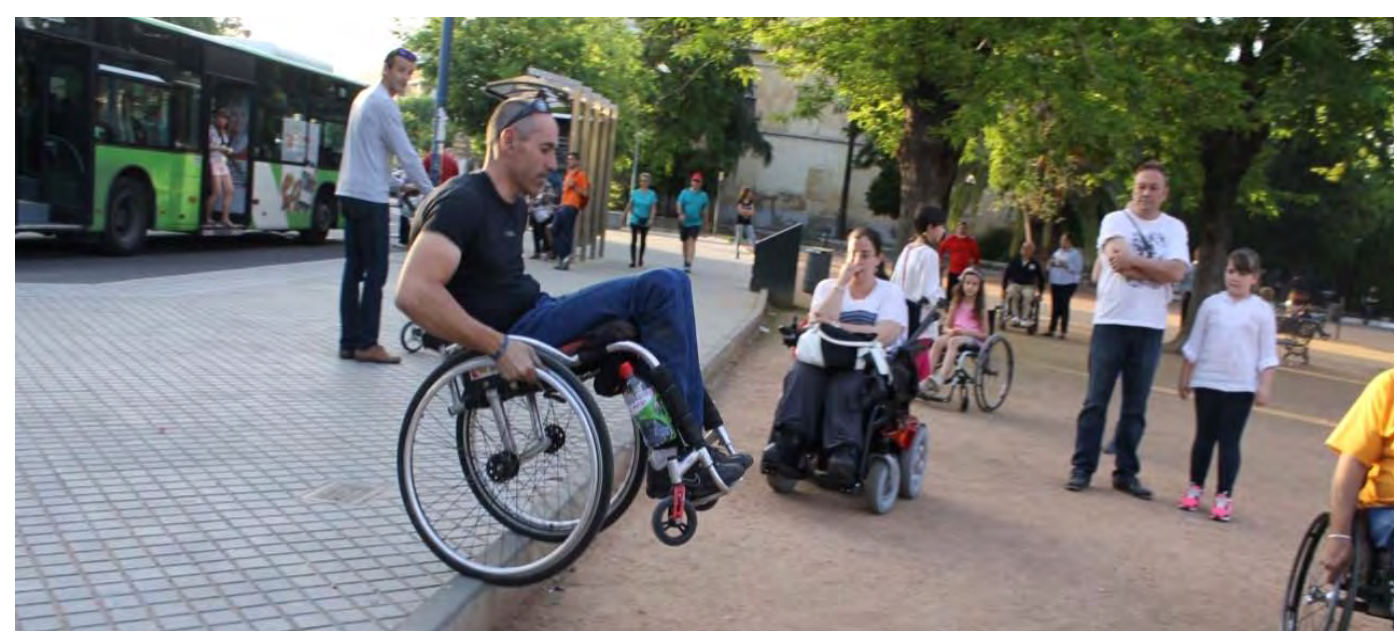

Nuestro deportista Alfonso realizando una exhibición de silla de ruedas para ASPAYM Córdoba.

"Mi padre tenía sentimientos de culpa por haberme comprado la moto. Yo nunca he pensado que tuviera la culpa, al contrario, hizo mi sueño realidad". "Mi madre me acompañó en todo momento. Lo malo es que yo tenía que ser fuerte para que mi madre no sufriera, no me ha permitido desahogarme".

Tiene mujer y dos niñas y hacen una vida normalizada como cualquier familia.

“Las niñas me decían: 'Papá, ¿cuándo te vas a levantar?’, ellas se acostumbran rápidamente, diferencian bien enfermedad de discapacidad".

Trabaja como formador de prevención vial:

"Me llena el trabajo que estoy realizando porque transmitir mi problema puede hacer que los chavales no pasen por esto $y$ concienciar a los infractores de lo que puede ocurrir".

Reconoce que “se pasa” con el deporte:

"Me he volcado demasiado, realizo deporte a diario, soy semiprofesional. Llevo siete años compitiendo, y cinco años subiendo al podio del Campeonato de España. Hay pocos patrocinadores y muchos gastos. Todo esto es tiempo que le quito a la familia, soy consciente de ello y me apena, pero es mi trabajo y mi satisfacción".

Esto son sólo algunos ejemplos de lo que podemos encontrar en ASPAYM Córdoba, personas con increíbles historias reales, vidas llenas de vida y días para afrontar lo que haga falta. Vidas que se han truncado por accidentes de tráfico, atracos o caídas, pero que han luchado por seguir adelante y que, gracias a los avances médicos y la atención apropiada, pero sobre todo a sus familiares y amigos, han tenido una segunda oportunidad.

También hay enfermedades que provocan lesiones medulares que se van agravando, algunas más lentas, otras rápidamente, y cuyas consecuencias son siempre las mismas: la dificultad para vivir de forma autónoma.

Por todos lados vemos que hay muchas más personas así, que encuentran continuamente complicaciones para desplazarse por casa, por la calle, para realizar las tareas diarias, para relacionarse con los demás o para trabajar, y desde ASPAYM Córdoba luchamos para reducir los riesgos de sufrir nuevos accidentes y que toda la sociedad tome conciencia y colabore para facilitar la integración y la igualdad de todos, porque son nuestros vecinos, nuestros amigos... nuestros iguales. 